$\underline{\text { Avicenna Journal of Nursing and Midwifery Care - ISSN 2676-5748 }}$

\title{
Relationship Between Nursing Communication Characteristics and Patient Safety Culture at Educational Hospitals in Sanandaj City
}

\author{
Zahra Mohammadi
}

Faculty of Nursing and Midwifery, Medical Sciences University of Kurdistan. Sanandaj, Iran

\begin{tabular}{|c|c|}
\hline Article Info & ABSTRACT \\
\hline $\begin{array}{l}\text { Received: } 2020 / 07 / 20 \\
\text { Accepted: } 2020 / 10 / 11 \\
\text { Published Online: } 2020 / 11 / 23\end{array}$ & $\begin{array}{l}\text { Introduction: The current study investigated the relationship between nurses' } \\
\text { communication features and patient safety culture in educational hospitals in Sanandaj city, } \\
\text { Iran. } \\
\text { Methods: This correlational study was performed on } 278 \text { nurses working in educational } \\
\text { hospitals in Sanandaj, Iran. The standard safety culture questionnaire made by Barton J.'s quality } \\
\text { and health care research and communication skills agency was used. The standard questionnaire }\end{array}$ \\
\hline \multirow{4}{*}{$\begin{array}{l}\text { Original Article } \\
\text { Use your device to scan } \\
\text { and read the article online }\end{array}$} & $\begin{array}{l}\text { used was in two sections. Data analysis was conducted using SPSS 19. In the descriptive statistics } \\
\text { section, mean and standard deviation, and in the inferential statistics, correlation tests, Mann- } \\
\text { Whitney, Kruskal-Wallis, and linear regression were used. }\end{array}$ \\
\hline & $\begin{array}{l}\text { Results: The mean of total positive responses to } 12 \text { dimensions of patient safety culture } \\
\text { was } 59.11 \% \text {. The negative response was } 22.07 \% \text { and the neutral responses were } 17.94 \% \text {. } \\
\text { These results indicated an acceptable status of safety culture in the studied hospitals. The } \\
\text { average of communication skills among nurses in Sanandaj was } 66.98 \pm 9.57 \text { (maximum score } \\
\text { is } 90 \text { ). The inferential analysis showed that there is a significant relationship between variables } \\
\text { such as age, work experience, marital status, educational level, and type of employment with } \\
\text { two main variables (communication skills and patient safety culture). The results of linear } \\
\text { regression showed that the components of communication skills (verbal, listening, and } \\
\text { feedback) have a positive and significant effect on improving the patient's safety culture. These } \\
\text { components may explain } 55.2 \% \text { of the variation of the dependent variable (the patient's safety } \\
\text { culture). }\end{array}$ \\
\hline & $\begin{array}{l}\text { Conclusion: Based on the results of the research, the status of the patient safety culture and } \\
\text { communication skills was moderate. To improve the patient's safety status, nurses' communication } \\
\text { skills should be improved. This is possible during the nurse's formal education or in-service training. }\end{array}$ \\
\hline & $\begin{array}{l}\text { Keywords: Safety culture, Nurse, Communication skills, Accidents, Medical errors, Health } \\
\text { care sector }\end{array}$ \\
\hline
\end{tabular}

Corresponding Information:

Zahra Mohammadi, Faculty of Nursing and Midwifery, Medical Sciences University of Kurdistan. Sanandaj, Iran Email: zahra.mohammadi1116@,gmail.com

Copyright $($ 2020, This is an original open-access article distributed under the terms of the Creative Commons Attribution-noncommercial 4.0 International License which permits copy and redistribution of the material just in noncommercial usages with proper citation.

How to Cite This Article:

Mohammadi Z. Relationship Between Nursing Communication Characteristics and Patient Safety Culture at Educational Hospitals in Sanandaj City. Avicenna J Nurs Midwifery Care. 2020; 28 (4): $73-82$ 
رابطهُ بين ويثزَىهاى ارتباطى يرستاران و فرهنَ ايمنى بيمار در بيمارستانهاى آموزشى شهر سنندج ز زمرا محمدى

دانشكده يرستارى و مامايى، دانشكاه علوميزشكى كردستان، سنندج، ايران

\begin{tabular}{|c|c|}
\hline جكيده & اطلاعات مقاله \\
\hline 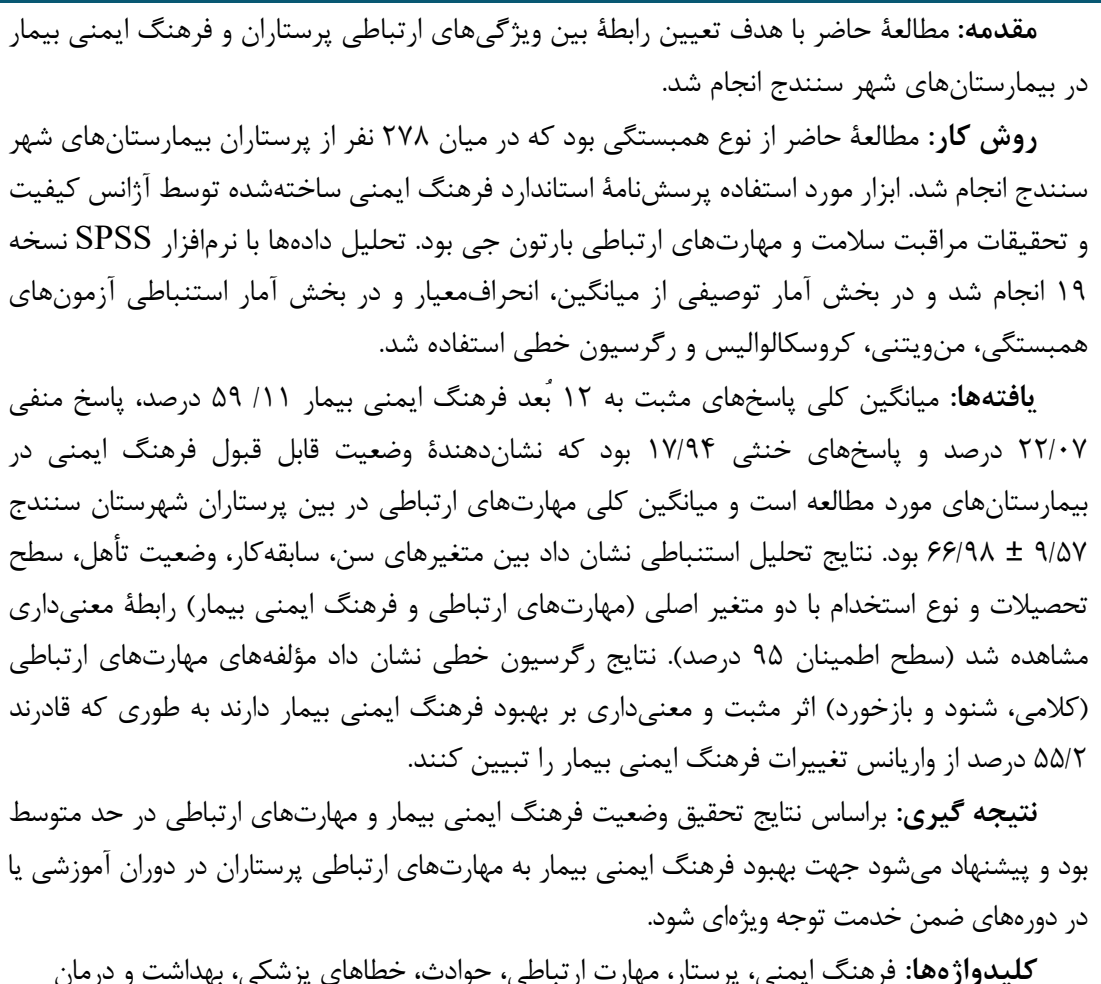 & 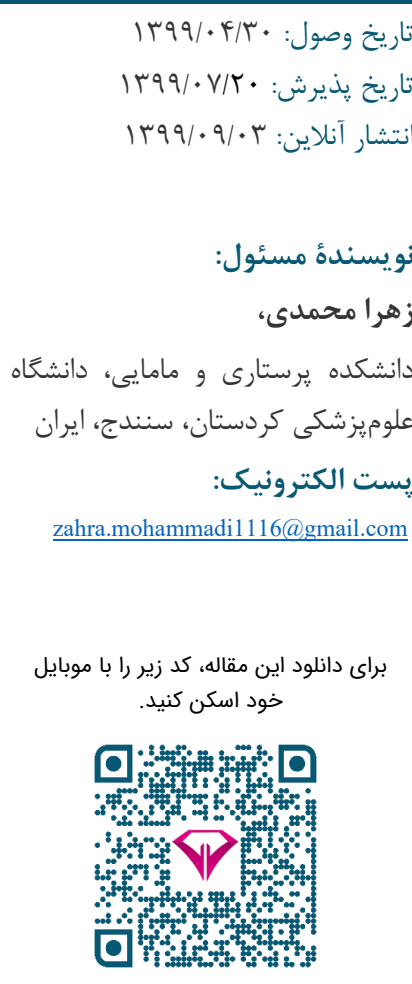 \\
\hline
\end{tabular}

بخش سلامت و به ويزه در مراكز درمانى است [ع] [ب] مطالعات

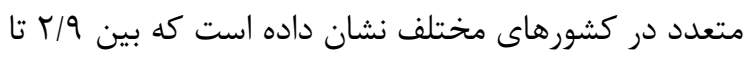
19/9 درصد از بيماران در بيمارستانهاى مراقبت حان حاد داد

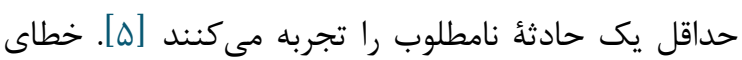

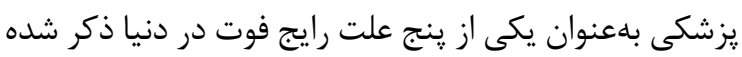

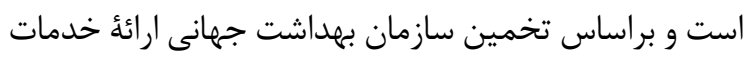
و مراقبتهاى يزشكى غيرايمن به آسيب و فوت دهمها بها ميليون

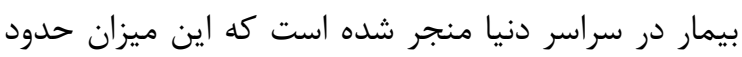

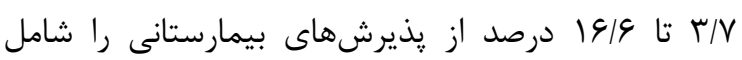

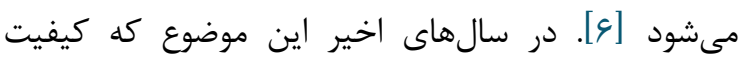

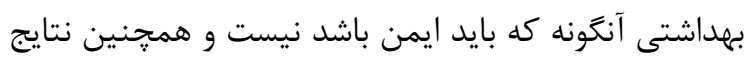

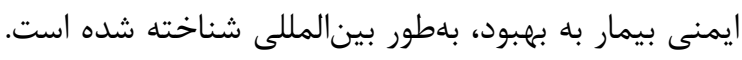

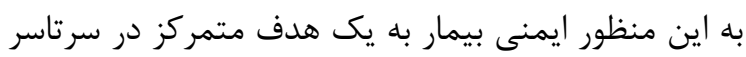

بيمارستانها يكى از مهمترين نهادهاى ارائهدهندة

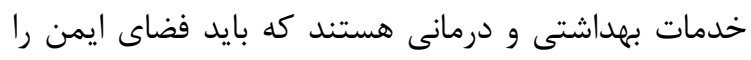

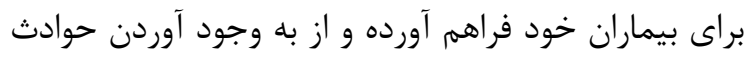

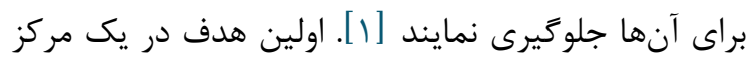

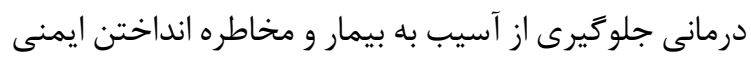

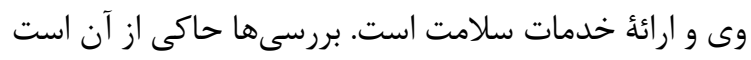

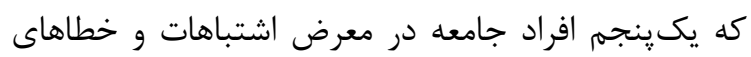

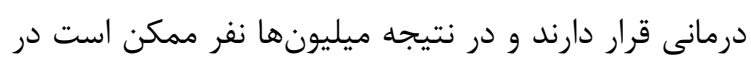

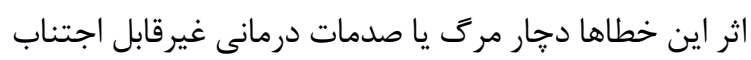

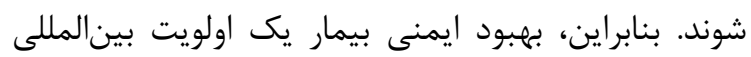

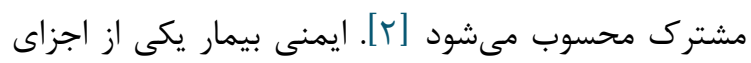

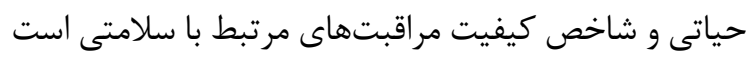

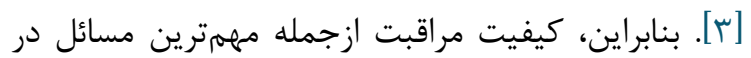


بيشترين گروه كار كنان بيمارستانها هستند. به دليل ماهيت

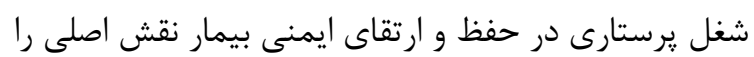

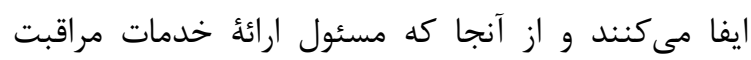

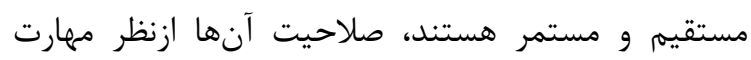

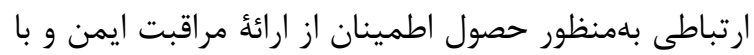

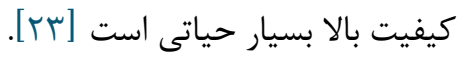

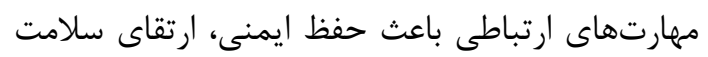
بيمار، كاهش اضطراب و فرسودىى شغلى در ميان يرستاران

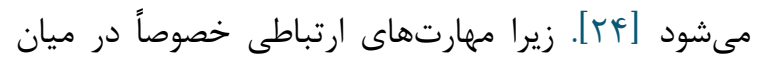

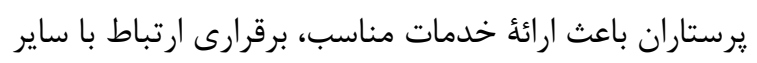

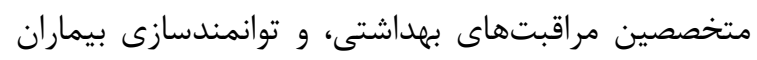

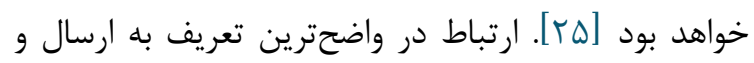

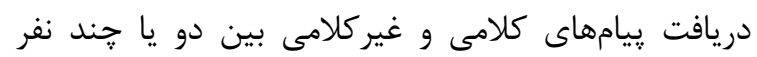

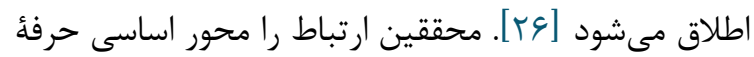

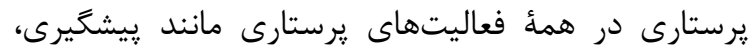

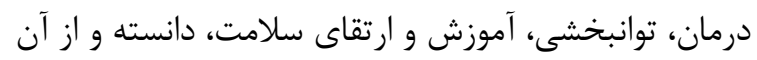

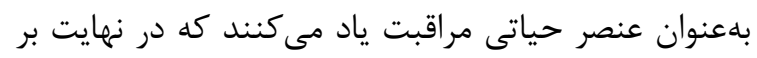

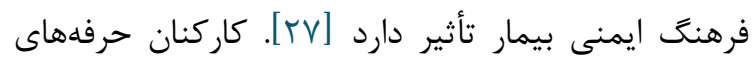
بهداشتى و درمانى به بهبود مهارتهاى ارتباطى نياز دارد دارني

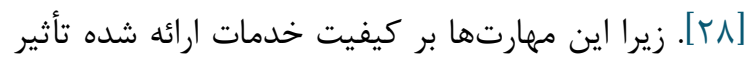

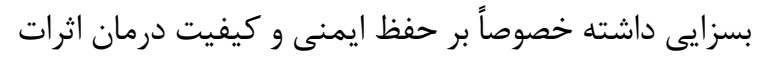

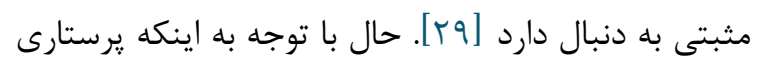

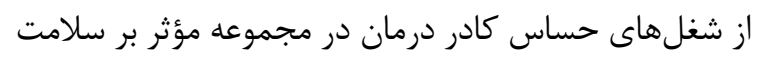

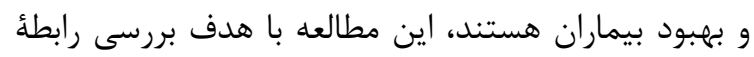

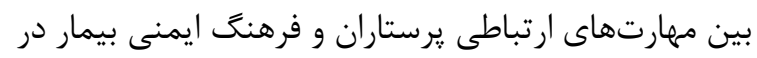
ميان بيمارستانهاى شهرستان سنندج انجام شد.

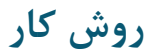

اين تحقيق ازنظر هدف كاربردى، ازنظر امكان كنترل

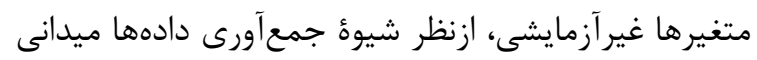

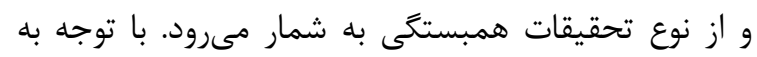

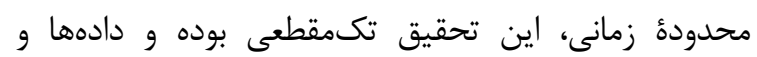

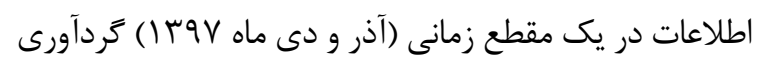

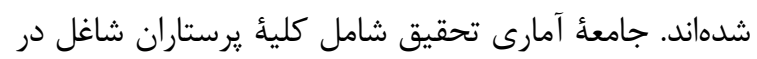

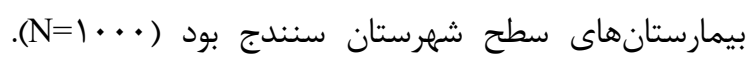

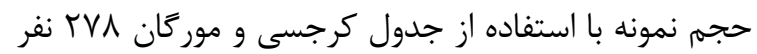

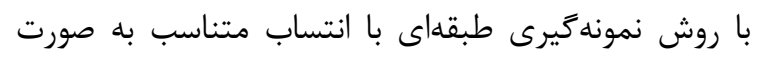

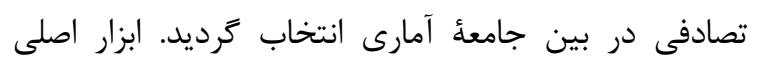

دنيا براى كاهش وقوع و تأثير خطاهاى انسانى در حوزه

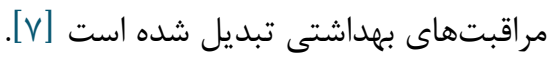

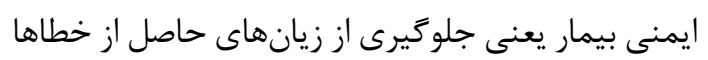

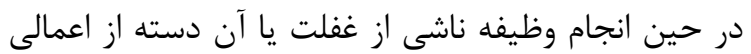

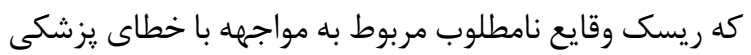

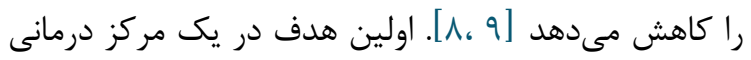

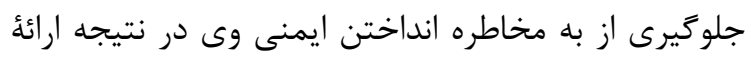

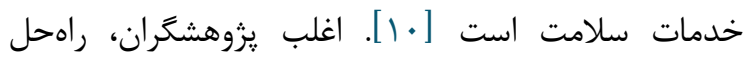

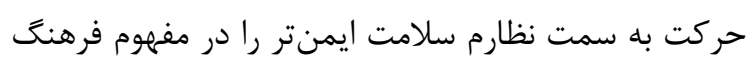

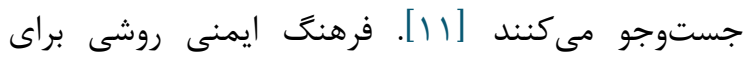
جلوكيرى از خطاى يزشكى است و بهبود فرهنگ مىتواند

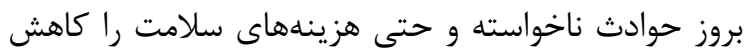

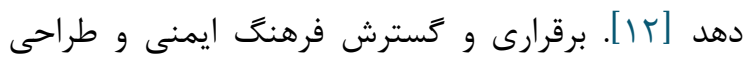

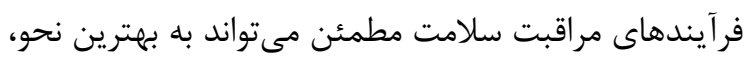

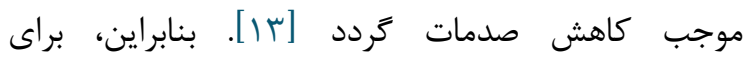
سازمانهاى بهداشتى و درمانى ضرورى است در فرآيندهاى

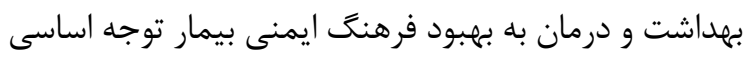

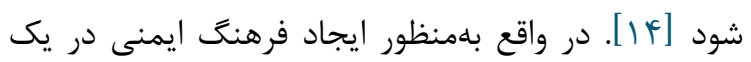

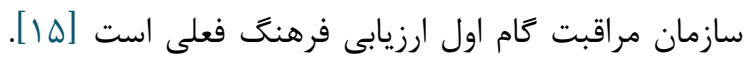

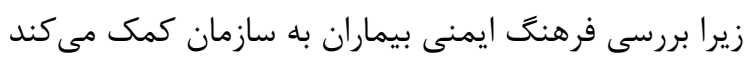

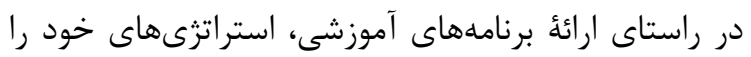

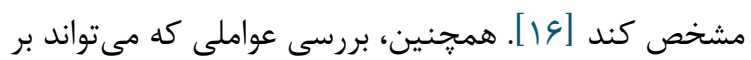

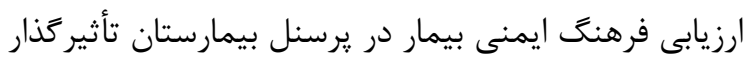

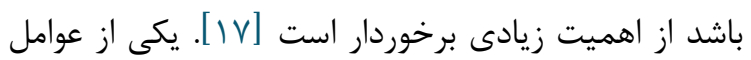

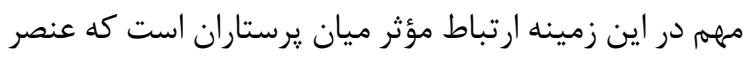

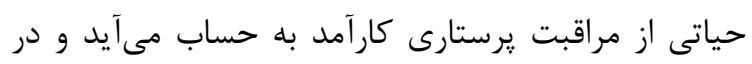

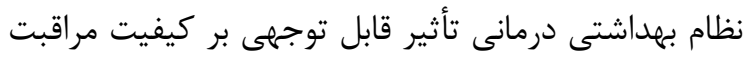

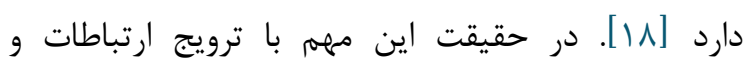

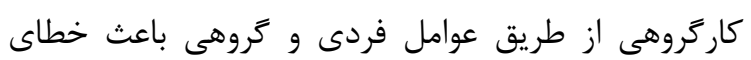

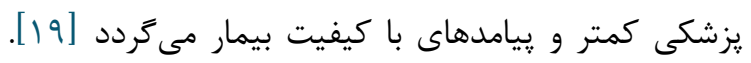

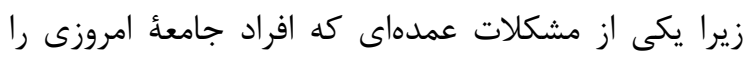
تهديد مى كند، عدم برقرارى ارتباط صحيح و درك همدلانه إنها

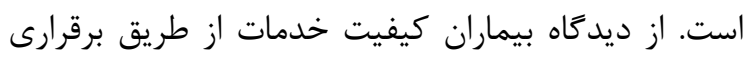

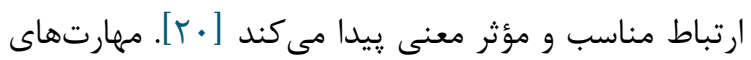

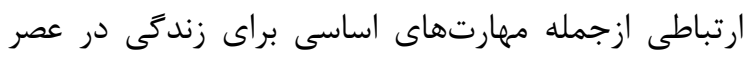

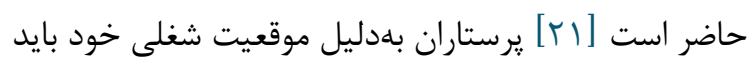

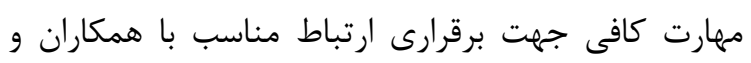

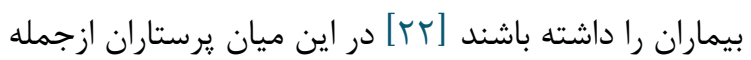




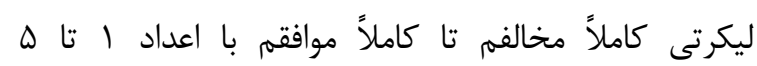

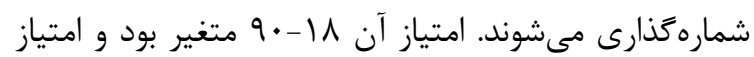

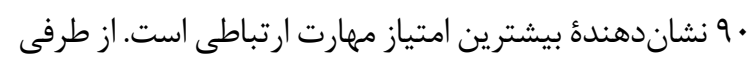

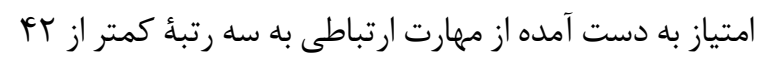

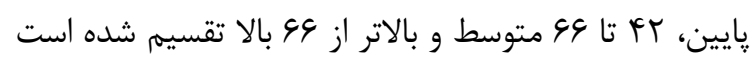

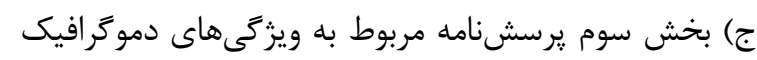
شامل سن، وضعيت تأهل، سطح تحصيلات و سابقه كار بود.

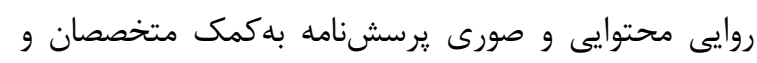

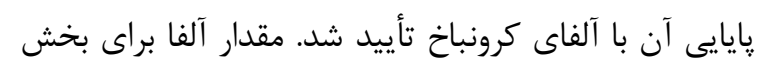

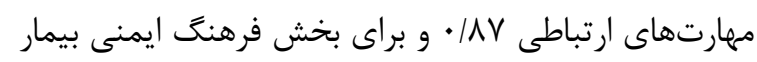

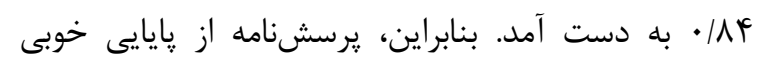

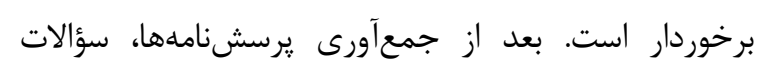

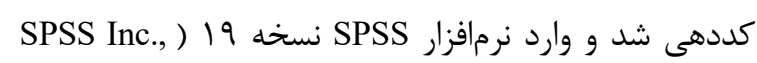
(Chicago, Ill., USA

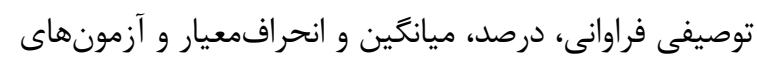

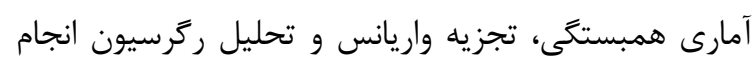

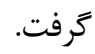

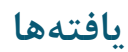

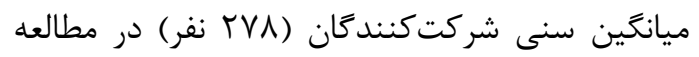
سن $9 / /$ F

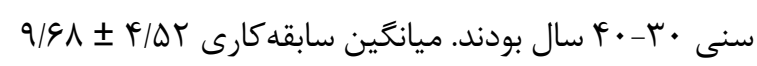

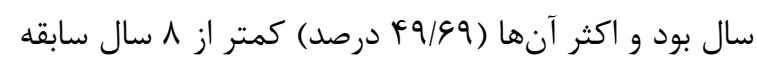

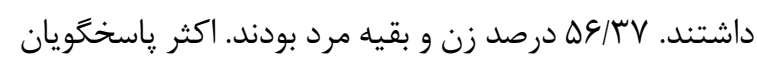

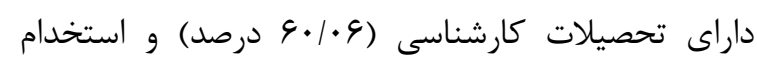

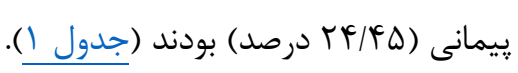

تحقيق، يرسشنامه بود كه دو بخش داشت: (الف) بخش اول

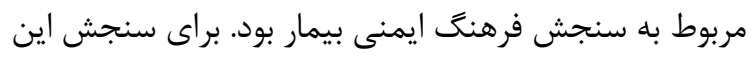
بخش از مدل استاندارد ساختهشده توسط آزانس كيفيت و ورئي

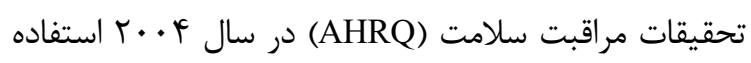

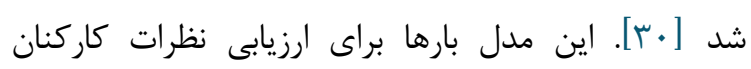

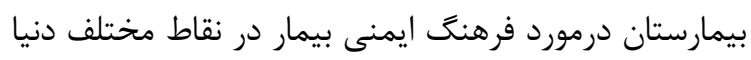

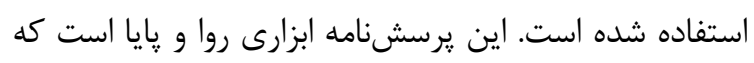

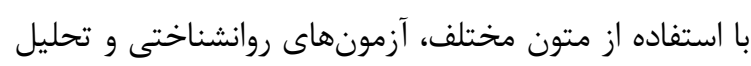

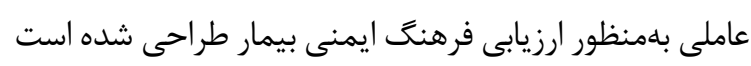

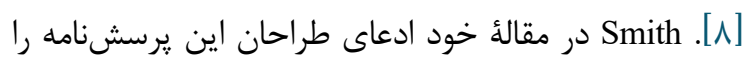

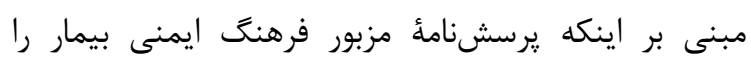

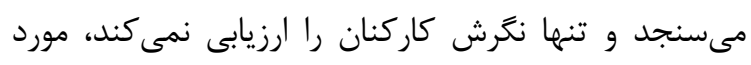

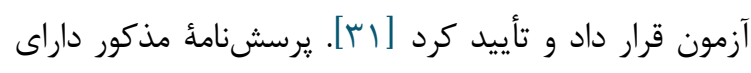

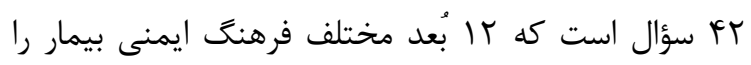

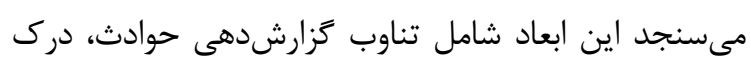

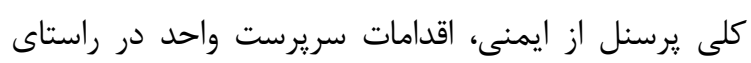

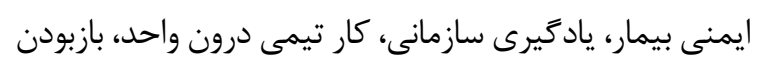

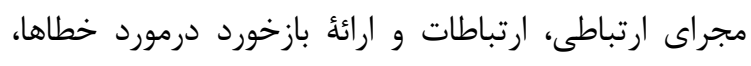

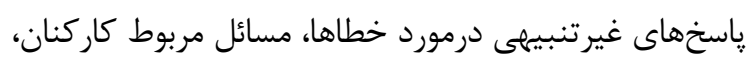

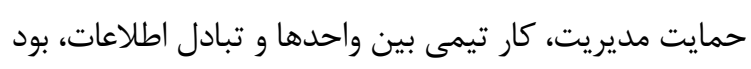

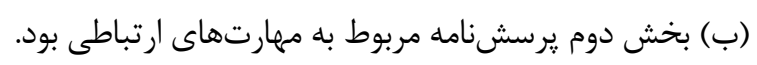

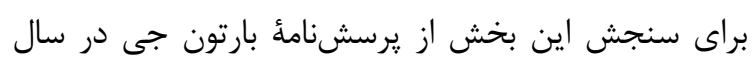

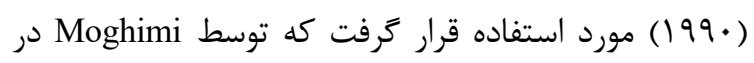
ايران روانسنجى و تاكنون در مطالعات مختلف ديكر نيز

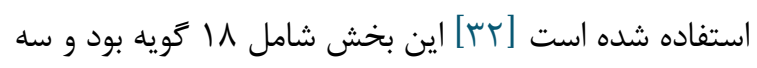
همارت كلامى، مهارت شنود و مهارت بازخورد را را مىسنجد.

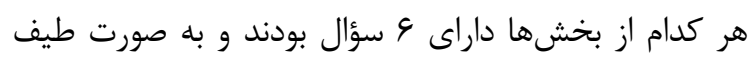

جدول ا. توزيع فراوانى شركتكنندًان در مطالعه

\begin{tabular}{|c|c|c|c|}
\hline درصد & تعداد & طبقه & متغير \\
\hline$r \Delta / r \Delta$ & 91 & مرد & \multirow{2}{*}{ جنسيت } \\
\hline$s \Psi / V \Delta$ & 11. & زن & \\
\hline سז/ & 1.1 & مجرد & \multirow{2}{*}{ وضعيت تأهل } \\
\hline$\varepsilon r / \varepsilon V$ & IVV & متأهل & \\
\hline$r q / \wedge \Delta$ & $\Lambda r$ & $<r$. & \multirow{3}{*}{ سن } \\
\hline$\Delta F / \mathscr{G}$ & IDT & $r \cdot-r \cdot$ & \\
\hline $\mid Q / F \wedge$ & Fr & $>r$. & \\
\hline$\Delta V / 19$ & 109 & $<\wedge$ & \multirow{2}{*}{ سابقه كار } \\
\hline$r \Lambda / \cdot \Delta$ & $\vee \wedge$ & ^ تا \1 سال & \\
\hline
\end{tabular}




\begin{tabular}{|c|c|c|c|}
\hline درصد & ت تعداد & طبقه & متغير \\
\hline IF/VE & \&l & $>11$ & \\
\hline$\left.V \wedge / \Psi^{\prime}\right)$ & rin & كارشناسى & \multirow{2}{*}{ سطح تحصيلات } \\
\hline$r I / \Delta 9$ & 4. & كارشناسىارشد و بالاتر & \\
\hline $1 \% / 99$ & ґ & رسمى & \multirow{6}{*}{ رابطؤ استخدامى } \\
\hline IV/KG & $\uparrow \wedge$ & آزمايشى & \\
\hline TF/FG & $9 \wedge$ & ي بيمانى & \\
\hline $1 \cdot / 4 r$ & rq & قراردادى & \\
\hline $19 / .9$ & Q & شركتى & \\
\hline 10/1 & ft & طرحى & \\
\hline
\end{tabular}

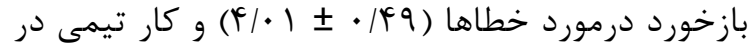
بين واحدهاى بيمارستانى (qq/ • مشترك بيشترين امتياز را داشتند و و مؤلفه تبادئل رادل

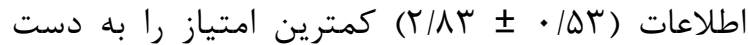
آورد. علاوهبر اين، در بررسى وضعيت مهارتهاى

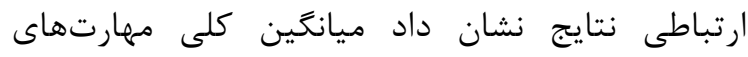
ارتباطى در بين يرستاران شهرستان سنندج 9/DV

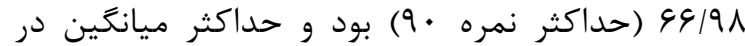
حيطه ها مربوط به مهارتهاى كلامى

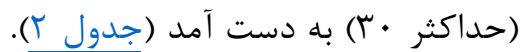

براساس نتايج، ميانگين كلى درصد ياسخهاى مثبت

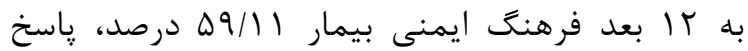

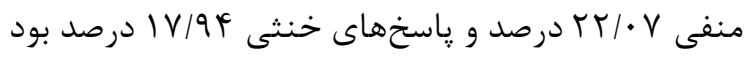
كه نشاندهنده وضعيت قابل قبول فرهنگ ايمنى در بيمارستانهاى موردمطالعه است. از طرفى بالاترين

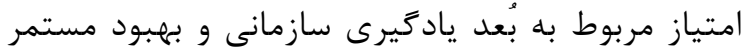

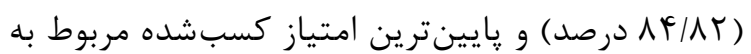

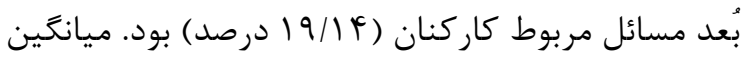

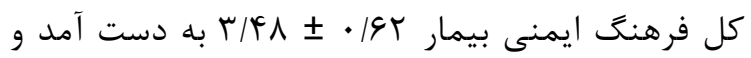
در ميان ابعاد فرهنَ ايمنى بيمار مؤلفه ارتباطات و ارائه

جدول r. ميانگَين و انحرافمعيار فرهنَ ايمنى بيمار و مهارتهاى ارتباطى بر ستاران

\begin{tabular}{|c|c|c|c|}
\hline انحر اف معيار & 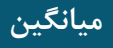 & 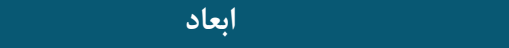 & متغير ها \\
\hline$\cdot 19 \Lambda$ & Y/AV & تناوب ززارشدهى حوادث & \\
\hline$\cdot|V|$ & $r / \uparrow \varphi$ & درك كلى نسبت به ايمنى بيمار & \\
\hline$\cdot|9|$ & r/Ar & اقدامات سريرست واحد در راستاى ايمنى بيمار & \\
\hline$\cdot / V T$ & $r / 9 \Lambda$ & يادَيرى سازمانى و بهبود مستمر & \\
\hline .194 & $\Gamma / \wedge \Delta$ & كار تيمى درون واحد & \\
\hline$\cdot \mid \mathrm{VI}$ & $r / \varepsilon \wedge$ & باز بودن مجراى ارتباطى & \\
\hline.$/ 49$ & $4 / \cdot 1$ & ارتباطات و ارائُٔ بازخورد درمورد خطاها & فرهنَ ايمنى \\
\hline$\cdot \operatorname{DST}$ & $r / 1 r$ & ياسخهاى غيرتنبيهى به خطاها & \\
\hline$\cdot|9|$ & $r / T \Delta$ & مسائل مربوط كاركنان & \\
\hline$\cdot / V T$ & r/A & حمايت مدير يت & \\
\hline$\cdot 109$ & $r / \cdot 1$ & كار تيمى در بين واحدهاى بيمارستانى & \\
\hline$\cdot \mid \Delta r$ & $r / \wedge \Delta$ & 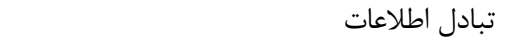 & \\
\hline$\cdot \operatorname{lar}$ & $r / \mathcal{F} \Lambda$ & فرهنَ ايمنى بيمار & \\
\hline
\end{tabular}




\begin{tabular}{|c|c|c|c|}
\hline انحرافمعيار & ميانَين & 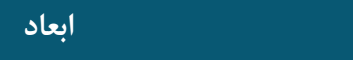 & متغيرها \\
\hline T/AV & $r r / \Delta q$ & كلامى & \\
\hline$r / T \Lambda$ & $r I / / V$ & 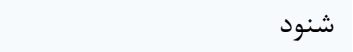 & مهارتهاى ارتباطى \\
\hline T/FT & TY/TY & بازخورد & \\
\hline
\end{tabular}

\begin{tabular}{|c|c|}
\hline تأهل، سطح تحصيلات و نوع استخدام با دو متغير اصلى & در ادامه تحليلهاى آمارى به بررسى روابط بين متغيرهاى \\
\hline (مهارتهاى ارتباطى و فرهنَ ايمنى بيمار) رابطةٔ معنى دارى & دمو گرافيك با دو متغير اصلى يزوهش (مهارتهاى ارتباطى و \\
\hline مشاهده شد. اين در حاليست كه بين متغير جنسيت و متغير & فرهنَ ايمنى بيمار) : يرداخته شد (جدول س). براساس نتايج \\
\hline آمارى وجود ندارد. & 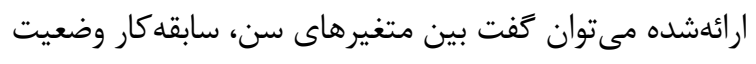 \\
\hline
\end{tabular}

جدول س. ارتباط بين متغير هاى دموكَرافيك با دو متغير اصلى يثروهش (مهارتهاى ارتباطى و فرهنَ ايمنى بيمار)

\begin{tabular}{|c|c|c|c|c|c|}
\hline \multicolumn{2}{|c|}{ متغير وابسته } & \multirow{2}{*}{ نوع آزمون } & \multirow{2}{*}{ فراوانى } & \multirow{2}{*}{ طبقات } & \multirow{2}{*}{ متغير هاى دموكر افيك } \\
\hline فرهنَ ايمنى & مهارتهاى ارتباطى & & & & \\
\hline & & \multirow{3}{*}{ همبستگى اسيّرمن } & 人 & $<r$. & \multirow{3}{*}{ سن } \\
\hline $1=0$ & & & IQT & $r \cdot-r$. & \\
\hline$P=\cdot / \cdot 10$ & $P=. / \cdot 1 \Delta$ & & fr & $>r$. & \\
\hline$r=\cdot / r v$ & $\mathrm{r}=\cdot / \mathrm{r} \wedge$ & \multirow{3}{*}{ همبستخى اسيّرمن } & 109 & $<\wedge$ & \multirow{3}{*}{ سابقه كار } \\
\hline$P=.1 .1 \Delta$ & $P=.1 .1 \Delta$ & & VA & ^ تا \1 سال & \\
\hline & & & (1) & $>11$ & \\
\hline $19 / 19 \pm r / r \wedge$ & $r \Delta / \Lambda \Lambda \pm r / \cdot l$ & \multirow{3}{*}{ منويتنى } & 91 & مرد & \multirow{3}{*}{ جنسيت } \\
\hline $1 N / 1 \Delta \pm r / r \Delta$ & $r q / 1 F \pm 1 / r \Delta$ & & \multirow{2}{*}{$1 \wedge}$. & \multirow[b]{2}{*}{ 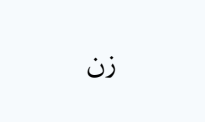 } & \\
\hline$P=\cdot / \mu \mid \Delta$ & $P=\cdot / \pi \mid \pi$ & & & & \\
\hline$|N / T F \pm T /| \mid$ & $r \Delta / V \Delta \pm 1 / r \Delta$ & \multirow{3}{*}{ منويتنى } & $1 \cdot 1$ & مجرد & \multirow{3}{*}{ وضعيت تأهل } \\
\hline $19 / \Delta T \pm 1 / T F$ & $r N / I T \pm 1 / r G$ & & \multirow{2}{*}{ IVV } & \multirow{2}{*}{ متأهل } & \\
\hline$P=\cdot / \pi \mid \pi$ & $P=\cdot \mid \cdot \cdot 1$ & & & & \\
\hline $\mid \Lambda / r \Delta \pm r / 1 \Lambda$ & $T F / T V \pm T / I I$ & \multirow{3}{*}{ منويتنى } & rMA & كارشناسى & \multirow{3}{*}{ سطح تحصيلات } \\
\hline$r I / 1 V \pm I / A V$ & $r V / \Lambda \Delta \pm r / \Delta T$ & & \multirow{2}{*}{ ६. } & كارشناسى ارشد و & \\
\hline$P=\cdot \mid \cdot \cdot 1$ & $P=\cdot / \cdot 1$ & & & بالاتر & \\
\hline$r \Lambda / I F \pm r / \Delta \Lambda$ & $r r / I F \pm 1 / r \Delta$ & \multirow{7}{*}{ كروسكالواليس } & rᄉ & رسمى & \multirow{7}{*}{ نوع استخدام } \\
\hline$r \varepsilon / F \mid \pm r / \cdot r$ & $r T / I F \pm T / F T$ & & F^ & آزمايشى & \\
\hline$r V / G \Delta \pm r / \Delta T$ & $r \mid / T I \pm T / r)$ & & $4 \Lambda$ & ييمانى & \\
\hline$r F / r \Delta \pm r / \cdot 1$ & $19 / 1 F \pm T / 1 T$ & & rq & قراردادى & \\
\hline$r r / / F \pm r / F r$ & IN/DT \pm T/IT & & $\Delta r$ & شركتى & \\
\hline $19 / \Delta T \pm T / T F$ & $|V / 1 \Delta \pm T /| F$ & & \multirow{2}{*}{ Ft } & \multirow{2}{*}{ طرحى } & \\
\hline$P=. / \cdots 1$ & $P=\cdot 1 \cdot \cdots 1$ & & & & \\
\hline
\end{tabular}


بيمار در بيمارستانهاى مطالعهشده به صورت زير به دست

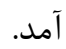

$\mathrm{Y}=15.949+2.82 \times 1+3.745 \times 2+2.435 \times 3$

كه در اين معادله Y: فرهنگ ايمنى بيمار و X1 تا X3

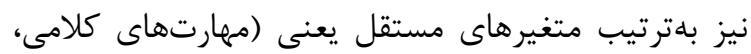

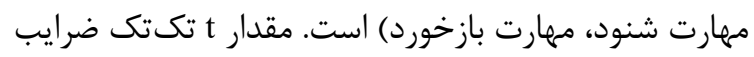

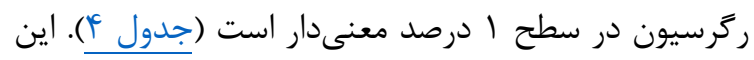
نشاندهنده آن است كه ابعاد متغيرهاى مستقل انتخابشده تأثيرى قوى بر پيش گويى فرهنگ ايمنى بيمار دارد.
نتايج تحليل رگرسيون جندمتغيره خطى به روش توام (Enter)

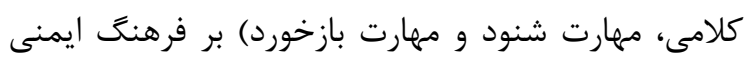

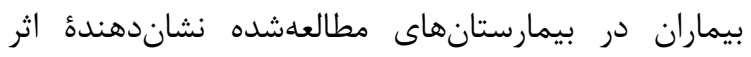
معنىدار سه مؤلفه بودند. مقدار بتا (Beta) مربوط بهان بهان

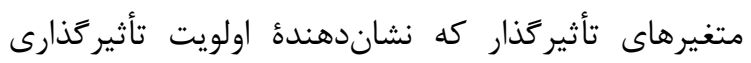

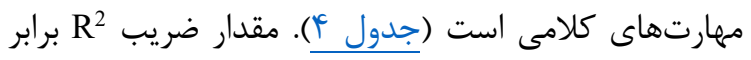

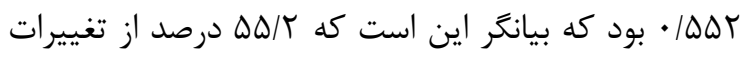

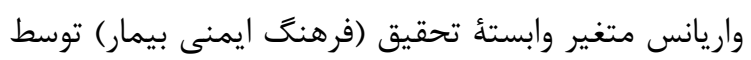

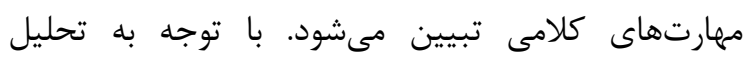

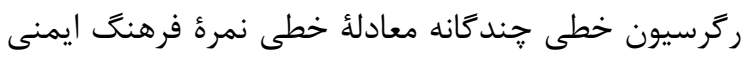

جدول F. ميزان تأثير مؤلفه مهارتهاى ارتباطى بر فرهنَ ايمنى بيمار

\begin{tabular}{|c|c|c|c|c|c|c|c|c|}
\hline $\mathbf{R}^{2} \mathbf{A d}$ & $\mathbf{R}^{2}$ & $\mathbf{R}$ & Sig. & $\mathbf{t}$ & Beta & $\begin{array}{l}\text { Std. } \\
\text { Error }\end{array}$ & B & متغيرهاى بيشبينى كننده \\
\hline & & & $\cdot 1 \cdot \cdot 1$ & $\Delta / \Delta 9 Y * * *$ & $\cdot|r \varepsilon|$ & $\cdot 1 \Delta \cdot \Delta$ & T/AT & - مهارت كلامى \\
\hline \multirow[t]{2}{*}{$\cdot / \Delta \Delta 9$} & - IDQT & $\cdot / V V T$ & $\cdot|\cdot|$ & G/r.r䊪米 & $\cdot / r \cdot 1$ & $\cdot 19 \cdot 4$ & $r / V^{k}$ & - مهارت شنود \\
\hline & & & $\cdot 1 \cdot \cdot 1$ & $\varphi / / 9 \vee * * *$ & $\cdot|r| 9$ & $\cdot \mid \Delta \Lambda$. & T/FTD & - مهارت بازخورد \\
\hline
\end{tabular}

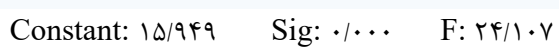

\section{بحث}

فرهنَ ايمنى بيمار مقدار ( نشاندهنده ميزان متوسط فرهنَ ايمنى بيمار است. نتايج

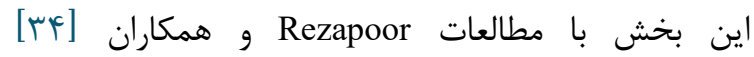
Mahfoozpour فرهنَ ايمنى بيمار را در بيمارستانهاى آموزشى دانشعاه علوميزشكى تهران و شهيدبهشتى در سطح متوسط برآ برود

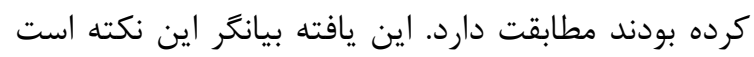
كه با توجه به حساسيت موضوع نياز مبرمى به به بهبود مبرد وضعيت فرهنَ ايمنى بيمار در بيمارستان مذكور دارد.

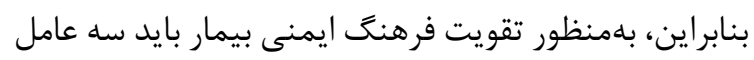

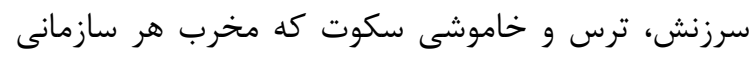
است را از محيطكار ريشهكن نمود. خطاها نبايد يوشيده

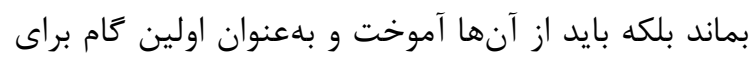
حذف صدمات ناشى از آنها و بيشرفت در زمينه ايمنى إنى بيمار استفاده شود [عب].

همجنين در بررسى ابعاد ז| فرهنَ ايمنى بيمار

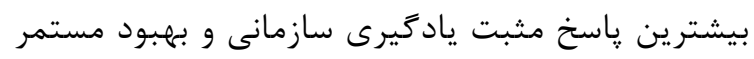

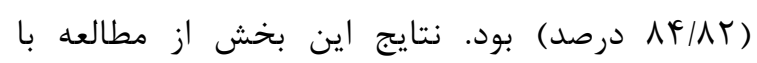

يكى از بحثهاى مهمم در بيمارستانها مفهوم فرهنگ ايمنى بيمار است كه موجب حركت بلهسوى ايمنترساختن

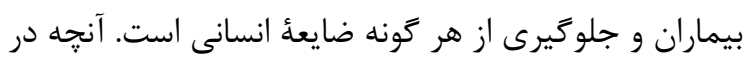
حال حاضر ضرورى به نظر مىرسد بررسى وضيعت فرهنى

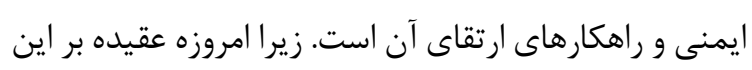

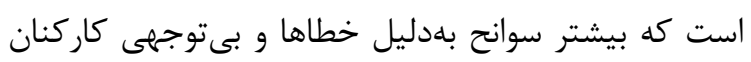

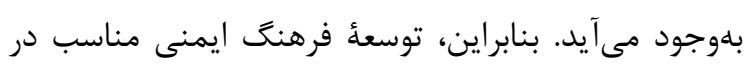

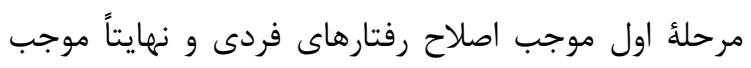

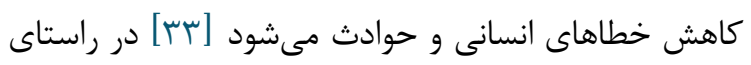

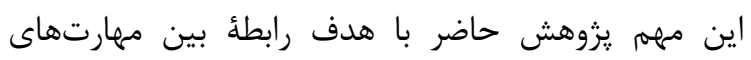

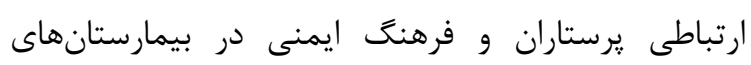

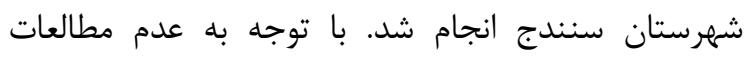

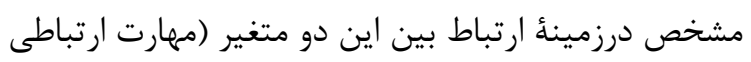

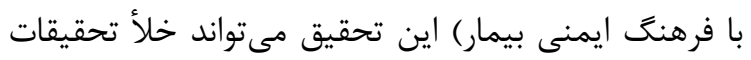
كذشته را تا حدودى ير كند. در ابتدا وضعيت فرهنَ ايمنى بيمار (HSOPSC) كه

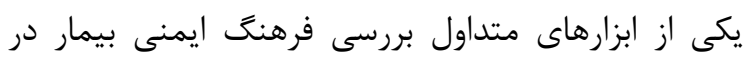

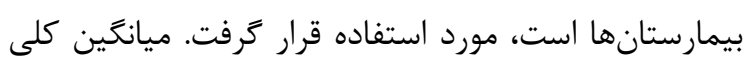


كه رابطهٔ مثبت و معنىدارى با متغيرهاى سن، وضعيت تأهل، سابقهكار، سطح تحصيلات و نوع استخدام دارد. نتايج اين

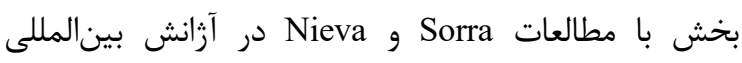

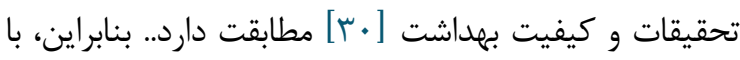

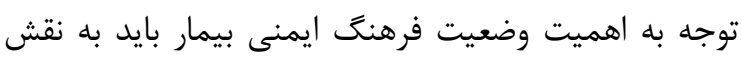

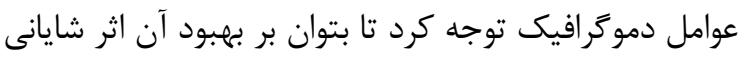

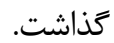
در نهايت در بررسى تأثير ويثگى هاى ارتباطى يرستاران

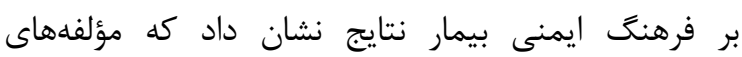

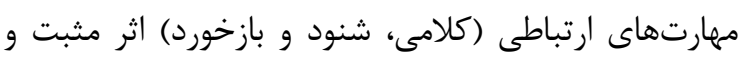

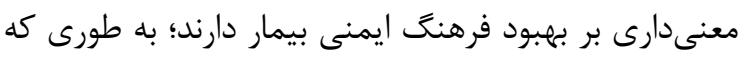

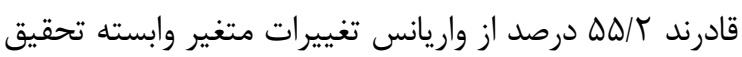

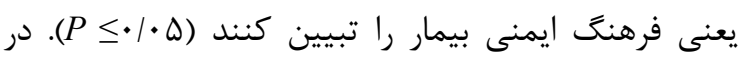

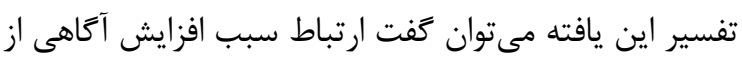

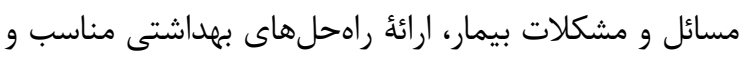

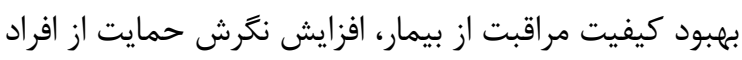
و كاركنان، افزايش حس مشاركت و همكارى در تيه درمانى،

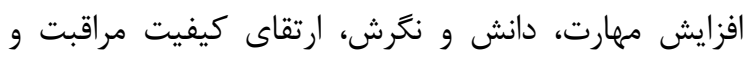

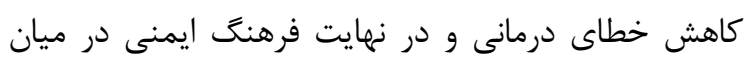
يرستاران خواهد شد [بrائ.

\section{نتيجه كيرى}

اين يزوهش با هدف بررسى رابطة بين ويزگى هاى

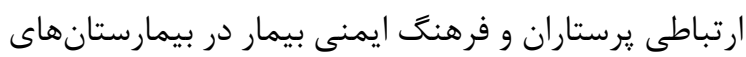

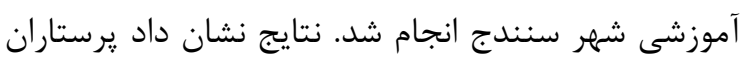

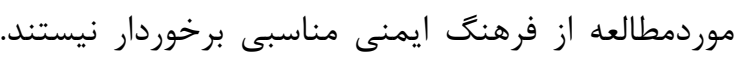

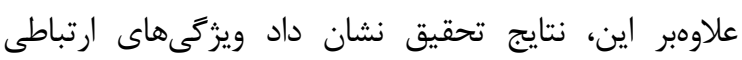

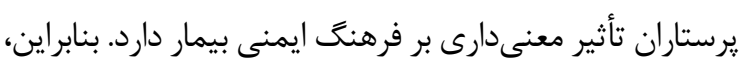

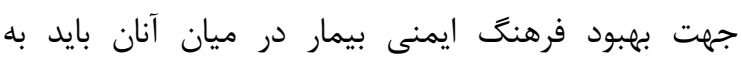

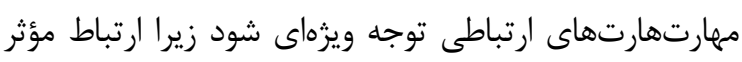

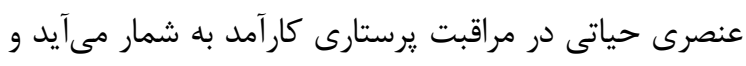
در نظام يزشكى تأثير قابلتوجهى بر كيفيت برستاريت مرارامد به نمار ميت دارد.

\section{سياسگزارى}

بدين وسيله از حمايتهاى دانشكاه علوميزشكى

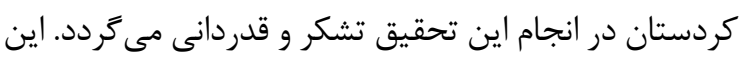

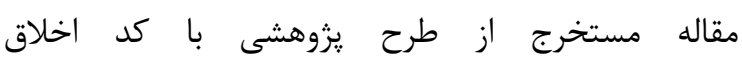

يافتههاى Sharifi و همكاران در بيمارستانهاى

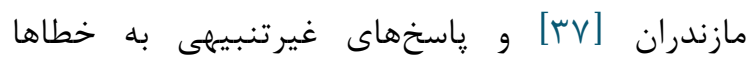
(19/1Y) يافتههاى Yaghoubi و همكاران در بيمارستانهاى

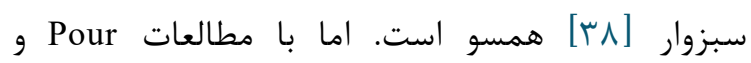

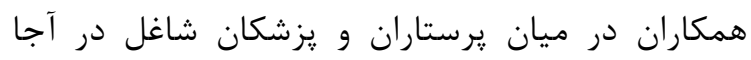

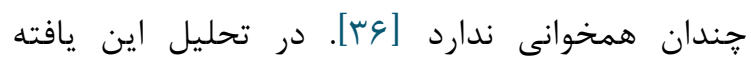

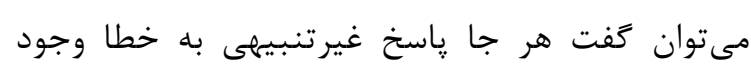

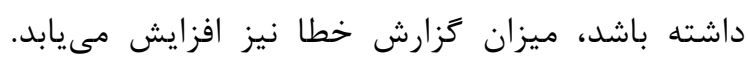

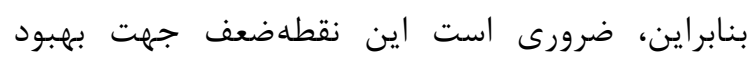
فرهنگ ايمنى بيمار ارتقاء يابد.

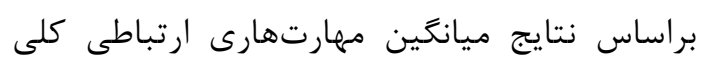

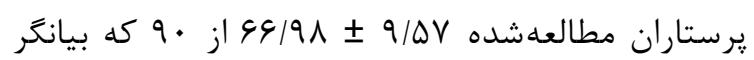
تقريباً سطح متوسط و قابل قبولى است كه با مطالعه Keshtkaran

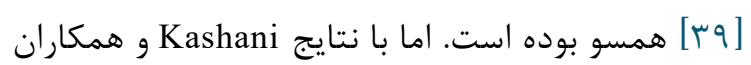

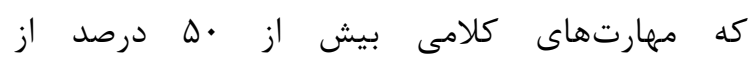

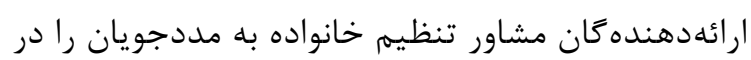

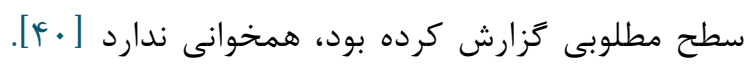

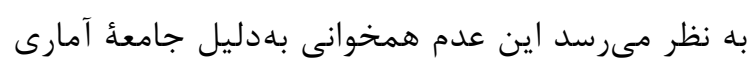

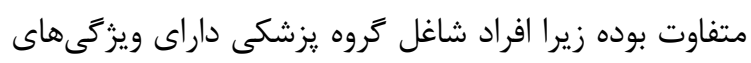

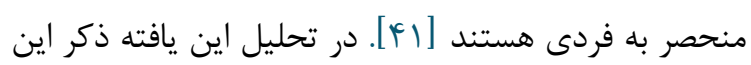

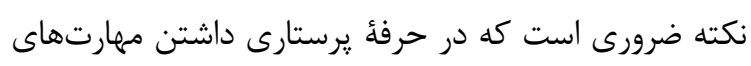

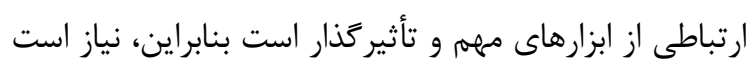

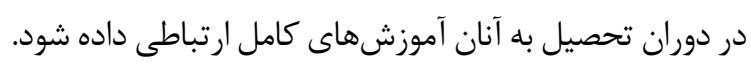

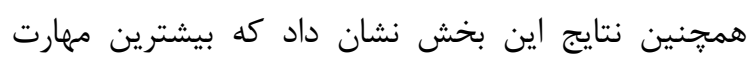
ارتباطى مربوط به مهارتهاى كلامى است كه بـ با مطالعه Barati

$$
\text { مطابقت دارد. }
$$

علاومبر اين، نتايج تحليل استنباطى نشان داد متادير

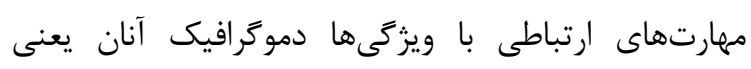

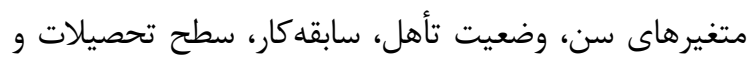

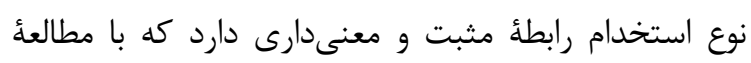

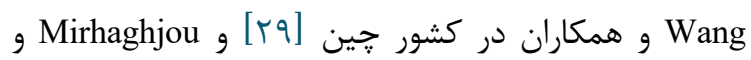

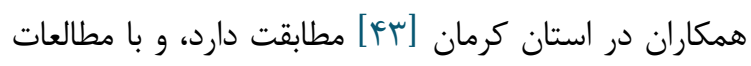
Rezaei

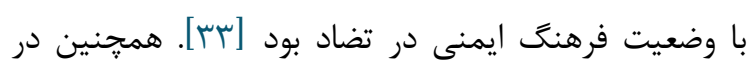

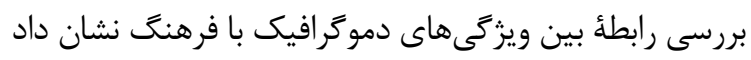


منابع مالى منابع مالى اين مطالعه توسط نويسندًان تامين شده است.

\section{References}

1. Nieva VF, Sorra J. Safety culture assessment: a tool for improving patient safety in healthcare organizations. Qual Saf Health Care. 2003; 12(2):17-23. [DOI:10.1136/qhc.12.suppl_2.ii17] [PMID] [PMCID]

2. Milligan F. Establishing a culture for patient safety - The role of education. Nurse Edu Today: 2007; 27:95102. [DOI:10.1016/j.nedt.2006.03.003] [PMID]

3. Smits M, Christiaans-Dingelhoff I, Wagner C, WalG, Groenewegen PP. The psychometric properties of the 'Hospital Survey on Patient Safety Culture' in Dutch hospitals. Health Serv Res. 2008; 8:230-237. [DOI:10.1186/1472-6963-8-230] [PMID] [PMCID]

4. Gupta B, Guleria K, Arora R. Patient safety in obstetrics and gynecology departments of two teaching hospitals in Delhi. India J Comm Med: Off Pub India Assoc Prev Soc Med. 2016; 41(3):235. [DOI:10.4103/0970-0218.183592] [PMID] [PMCID]

5. Bavil DA, Dolatian M, Mahmoodi Z, Baghban AA. Comparison of lifestyles of young women with and without primary dysmenorrhea. Elec Phys. 2016; 8(3):2107. [DOI:10.19082/2107] [PMID] [PMCID]

6. Hwang JI. What are hospital nurses' strengths and weaknesses in patient safety competence? Findings from three Korean hospitals. Int J Qual Health Care. 2015; 27(3):232-8. [DOI:10.1093/intqhe/mzv027] [PMID]

7. Johnstone MJ. Patient safety ethics and human error management in ED contexts: Part I: Development of the global patient safety movement. Aust Emerg $\begin{array}{llll}\text { Nurs } & \text { J. } & 2007 ; & 10(1): 13-20\end{array}$ [DOI:10.1016/j.aenj.2006.09.002]

8. Bodur S, Filiz E. A survey on patient safety culture in primary healthcare services in Turkey. Int J Qual Health Care. 2009; 21(5):348-55. [DOI:10.1093/intahe/mzp035] [PMID]

9. Ilan R, Fowler R. Brief history of patient safety culture and science. J Crit Care. 2005; 20(1):2-5. [DOI:10.1016/j.jcrc.2005.02.003] [PMID]

10. McGlynn EA. The quality of health care delivered to adults in the United Stated. N Engl J Med. 2003; 348:2681-3. [DOI:10.1056/NEJMsa022615] [PMID]

11. Adams RE, Boscarino JA. A community survey of medical errors in New York. Int J Qual Health Care. 2004; 16(5):353-62. [DOI:10.1093/intqhe/mzh063] [PMID]
12. Vifladt A, Simonsenc BO, Lydersend S, Farup PG. Changes in patient safety culture afterrestructuring of intensive care units: Two cross-sectional studies. Inten Crit Care Nurs. 2016; 32:58-65. [DOI:10.1016/j.iccn.2015.06.004] [PMID]

13. Verklan MT, Walden M. Core Curriculum for Neonatal Intensive Care Nursing [Book on CD-ROM]. Avaivable on: https://www.amazon.com/CurriculumNeonatalIntensive-NursingAWHONN/dp/032322590X.

14. Chen IC, Li HH. Measuring patient safety culture in Taiwan using the Hospital Survey on Patient Safety Culture (HSOPSC). BMC Health Serv Res. 2010; 10(1):152. [DOI:10.1186/1472-6963-10-152] [PMID] [PMCID]

15. Zendegani N, Zare zadeh N, Montaseri AM, Rabei $\mathrm{S}$. Evaluating patient's safety from the perspective of health-care officials in hospitals affiliating with Jahrom University of Medical Sciences in 2014. J Edu Ethic Nurs. 2015; 3(4): 49-55.

16. James JT. A new, evidence-based estimate of patient harms associated with hospital care. J Patient Safety. 2013; 9(3):122-8 [DOI:10.1097/PTS.0b013e3182948a69] [PMID]

17. Abdi ZH, Maleki MR, Khosravi A. Extracting staff from patient safety culture in selected hospitals of Tehran University of Medical Sciences. Payesh. 2011; 10(4):411-9.

18. Fakhr-Movahedi A, Salsali M, Negarandeh R, Rahnavard Z. Exploring contextual factors of the nurse-patient relationship: A qualitative study. Koomesh. 2011; 13(1):23-34.

19. Melissa DZ, McCarroll ML, Mendise TM, Ferris EF, Roulette GD, Zolton J, et al. Safety Culture in the Gynecology Robotics Operating Room. J Min Inv Gynecol. 2014; 21(5): 893-900. [DOI:10.1016/j.jmig.2014.03.027] [PMID]

20. Rabiei N, Gholami Fesharaki M, Maleki S, Mohamadian M. Relationship between burnout, job satisfaction and demographic factors with the level of patient safety culture in military healthcare staff. J Mil Med. 2018; 19(6):571-8.

21. Davati A, Vatankhah S, Sharifi K. Assessment of patient safety culture at Shahid Mostafa Khomeini Hospital: nurses' perspective. J Health Admin (JHA). 2018; 20(70):10-21.

22. Hosseini M, Sedghi Goyaghaj N, Alamadarloo A, Farzadmehr M, Mousavi A. The relationship between job burnout and job performance of clinical nurses in Shiraz Shahid Rajaei hospital (thruma) in 2016. J Clin Nurs Midwifery. 2017; 6(2):59-68 
23. Ammouri AA, Tailakh AK, Muliira JK, Geethakrishnan R, Al Kindi SN. Patient safety culture among nurses. Int Nurs Rev. 2015; 62(1):102-10. [DOI:10.1111/inr.12159] [PMID]

24. Qin CH, Xie J, Jiang J, Zhen F, Ding S. Reporting Among Nurses and Its Correlation with Hospital Safety Culture. J Nurs Care Qual. 2015; 30(1): 77 83. [DOI:10.1097/NCQ.0000000000000068] [PMID]

25. Vifladt A, Simonsenc BO, Lydersend S, Farup PG. Changes in patient safety culture after restructuring of intensive care units: Two cross-sectional studies. Inten Critic Care Nurs. 2016; 32, 58-65.

26. Wigham C, Chanier T. A study of verbal and nonverbal communication in Second Life-the ARCHI21 experience. ReCALL. 2013; 25(01):6384. [DOI:10.1017/S0958344012000250]

27. Wloszczak-Szubzda A, Jarosz MJ. Professional communication competences of nurses -- a review of current practice and educational problems. Ann Agric Environ Med. 2013; 20(1):183-8.

28. Barnard A, Ganca L. Using communication skills for difficult conversations in palliative care:'Suffering is not a question which demands an answer, It is not a problem which demands a solution, It is a mystery which demands a "Presence".'(Anonymous). Cont Med Educ. 2011;29(7)

29. Wang W, Liang Z, Blazeck A, Greene B. Improving Chinese nursing students' communication skills by utilizing video-stimulated recall and role-play case scenarios to introduce them to the SBAR technique. Nurse Edu Today. 2015; 35(7):881-7. DOI: 10.1016/j.nedt.2015.02.010 PMID: 25753352. [DOI:10.1016/j.nedt.2015.02.010] [PMID]

30. Sorra J, Nieva VF. Hospital survey on patient safety culture. Maryland: Agency for Healthcare Research and Quality; 2004.

31. Bognár A, Barach $\mathrm{P}$, Johnson JK, Duncan RC, Birnbach D, Woods D, Holl JL, Bacha EA. Errors and the burden of errors: attitudes, perceptions, and the culture of safety in pediatric cardiac surgical teams. Ann Thor Surgery. 2008; 85(4):1374-81. [DOI:10.1016/i.athoracsur.2007.11.024] [PMID]

32. Moghimi M. [Sazman va Modiriat: Rooykardi Pajooheshi]. 8th ed. Tehran: Termeh; 2011.

33. Rezaei Baghebidi MH, Halvani G, Ghiyasi S, Dehghani Tafti A. Assessing Safety Culture and its Influencing Factors in a Steel-Manufacturing Plant. Tolooe Behdasht. 2017; 16(4):37-48

34. Rezapoor A, Tanoomand Khoushehmehr A, Bayat R, Arabloo J, Rezapoor Z. Study of patients' safety culture in Selected Training hospitals affiliated with Tehran university of medical sciences. Hospital. 2012; 11(2): 55-64.

35. Mahfoozpour S, Eini E, Moasheri F, Faramarzi A Study of patient safety culture in teaching hospitals affiliated to Shahid Beheshti University of Medical Sciences in 2012. Pajoohande. 2012; 17(3):134-41.

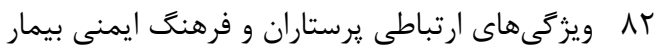

36. Pour RM, Fatemi, MA. Evaluation of Patient Safety Culture Based on the Viewpoint of Nurses and Physicians Employed in a Military Hospital. J Milit

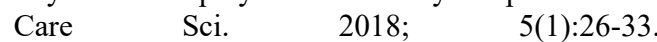
[DOI:10.29252/mcs.5.1.26]

37. Sharifi S, Izadi-Tame A, Hatamipour K, Sadeghigooghary N, Safabakhsh L. Patient Safety Culture from Mazandaran Clinical Nurses' Perspective. Iran J Nurs. 2014; 27(88):77-87. [DOI:10.29252/ijn.27.88.77]

38. Yaghobi Far MA, Takbiri A, Haghgoshaye E, Tabarraye Y. The survey of patient safety culture and recognizing its Weaknesses and strengths in Sabzevar hospitals. J Sabzevar Univ Med Sci. 2011; 20(2):154-64.

39. Keshtkaran A, Heidari A, Bastani P. Study of managers' communication skills based on the staff's view in Shiraz University of Medical Sciences. J Payavard Salamat. 2012; 5(4):41-8

40. Kashani F, Kashani P, Moghimian M, Shakour M. Effect of stress inoculation training on the levels ofstress, anxiety, and depression in cancer patients. Iran J Nurs Midwifery Res. 2015; 20(3):359-64.

41. Pakgohar M, Rahimikian F, Mehran A, Mohammadi T. Quality assessment of family planning counseling in health and treatment centers, affiliated to Tehran University of Medical Sciences. Hayat. 2002; 8(2):62-71.

42. Barati M, Afsar A, Ahmadpanah M. Assessment of communication skills level among healthcare practitioners. Avicenna J Clin Med. 2013; 19(1):629.

43. Mirhaghjou S, Nayebi N, Majd Teymouri R, Kazemnejadleily E. Communication skills and related factors within patient by nursing student. J Nurs Midwifery Fac. 2013; 25(76):93-101.

44. Burke ME, LeBlanc RG, Henneman EA. ABCDs of professional introductions: teaching nursing students the most fundamental of all communication skills. Nurse Edu. 2016; 41(3):115-6. [DOI:10.1097/NNE.0000000000000216] [PMID]

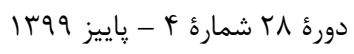

